\title{
Theories of opportunity creation and effective entrepreneurial actions in opportunity creation context
}

\author{
Behrooz Jamali $^{a}$, Reza MohammadKazemi ${ }^{b^{*}}$, Jahangir Yadollahi Farsi ${ }^{\text {b }}$ and Ali Mobini \\ Dehkordi $^{b}$
}

${ }^{a}$ PhD Candidate in Faculty of Entrepreneurship, University of Tehran, Tehran, Iran ${ }^{b}$ Associate Professor in Faculty of Entrepreneurship, University of Tehran, Tehran, Iran

\begin{tabular}{l}
\hline C H R O N I C L E \\
\hline Article history: \\
Received August 12, 2017 \\
Received in revised format: \\
December 20, 2017 \\
Accepted January 7, 2018 \\
Available online \\
January 7, 2018 \\
\hline Keywords: \\
Opportunity creation \\
Entrepreneurial opportunity \\
Entrepreneurial actions
\end{tabular}

\section{Introduction}

Technological entrepreneurship is a kind of theory of creating a new business that satisfies the needs of customers and society through a unique and novel combination of sources of technology and it has different benefits like wealth, occupation, value and progress (Alvarez et al., 2015). Petti (2009) defines technological entrepreneurship as identifying, discovering, and even generating entrepreneurial opportunities from technological advances. Accordingly, opportunity creation has a fundamental role in technological entrepreneurship theory. In addition, he conceives technological entrepreneurship as a combination of two concepts. The first is the technology defined by Burgelman et al. (2004) as theoretical and practical knowledge as well as skills and artifacts that can be used to develop products and services and systems of their production and delivery. The second one is entrepreneurship which is defined by Hitt et al. (2001) through identifying untapped opportunities and exploiting them by

* Corresponding author. Tel.: +989121345955

E-mail address: r_mkazemi@ut.ac.ir (R. Mohammad Kazemi)

(c) 2018 by the authors; licensee Growing Science, Canada. doi: $10.5267 / j . d s 1.2018 .1 .003$

(1) 
creating new resources or combining existing ones using new methods in order to develop and commercialize new products in new markets or to offer services to new customers (Petti, 2009). Petti (2009) takes a process look at technological entrepreneurship and conceives it as the process of adaptation between imagination and requirements. Therefore, in this approach, technological entrepreneurship is not the result of talented minds but is the result of combining conscious people with collective actions. According to this rational, technological entrepreneurship is a process that links technology with business creation and includes recognition or even creation of business values for new technologies and discoveries, adapting existing or potential market requirements, and it ultimately turns opportunities into new products, business services, and businesses. He considers four sets of activities for technological entrepreneurship: creating new technology or determining not exploited existing technology, identifying and adapting the opportunities for using these technologies to satisfy the needs of the new market, developing technology or applying it and creating business. The process of technological entrepreneurship which is based on the theory presented by Petti (2009) is demonstrated in Fig. 1.

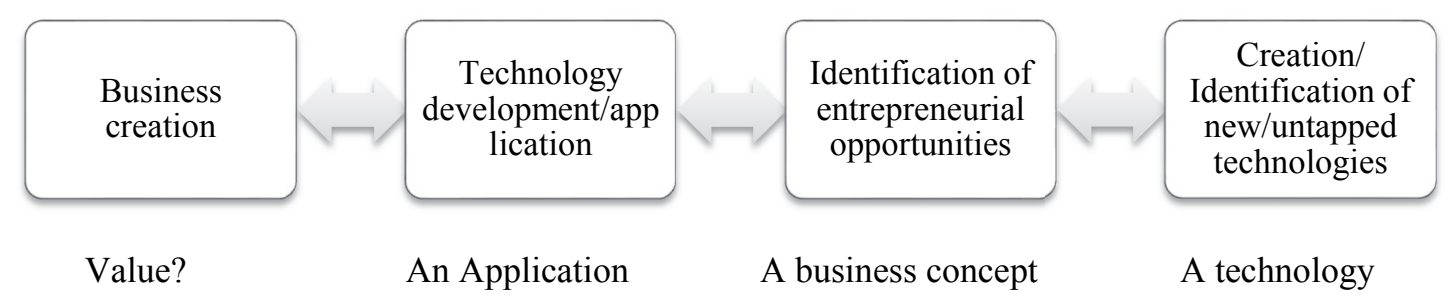

Fig. 1. A systematic approach to technological entrepreneurship

Blanco (2007) recommends a mental approach of building for the study of technological entrepreneurship based on the categorization proposed by Davidsson (2004) of the nature of opportunity. Technological entrepreneurship comes with offering substantial changes to the market; it is something new or significantly different that would be created and exploited and its form relies on the mental reflection of entrepreneurs and market conditions. In this approach, opportunity is generated in the mind of the entrepreneur using creative thinking and external conditions are taken into account and the credit of opportunity is never verifiable from the beginning but is recognized at the end of the process. Accordingly, this research has addressed the concept and theories of opportunity creation. Moreover, entrepreneurial actions influencing opportunity creation have also been investigated. Seven main actions have been determined and formulated in a model according to previous studies. Finally, discussions and conclusions are presented.

\section{Concept of opportunity creation}

In creation theory, opportunities for building and selling new products or services do not exist until entrepreneurs make it (Alvarez \& Barney, 2007). In this theory, entrepreneurs do not first recognize the opportunity and then take the necessary action but they take an action and then wait to learn the results of their actions in the market, and then re-take corrective actions based on feedbacks (Weick, 1979). In these actions, entrepreneurs generate opportunities that could not be learnt without taking those actions. In this setting, the formation of opportunities in creation theory is a process which relies on the path (Arthur, 1989) and is emerging (Mintzberg \& Waters, 1985). In this action and reaction, entrepreneurs build opportunities in accordance with the enactment process (Weick, 1979). Entrepreneurs may have hypotheses about how the market influence on their efforts but they are rarely able to see the end from the beginning. This is because in creation theory, there is no end until creation process appears. That is opportunities can only be learned when they are available and they only come into being when they are enacted in a reiterative process of action and reaction (Alvarez \& Barney, 
2007). Therefore, opportunities require human action for the formation, and social agreement for sustainability (Alvarez et al., 2013).

Dimov (2007) perceives this process as a move on a path from the initial idea to a full idea which is an opportunity. He stated that not any idea is a good opportunity and he believes that while every opportunity originates from an initial idea, the existence of ideas is a necessary but not sufficient condition for the emergence of opportunities. The condition of sufficiency relies on collecting evidence of the potential for profitability, the availability of a potential market, the capability to profitably and sustainably in profitability over the time horizon. Therefore, the idea is an abstract representation of the concept of future reality while opportunity tends to the realization of reality. After an idea appears, the entrepreneur modifies the idea by talking to friends and others and the new idea is more justifiable at least from the theoretical point of view. This cycle is repeated and more formal actions may be accomplished to pursuit the idea or the idea may be abandoned when people have come to conclusion that it cannot be justified. Regardless of the outcome that maybe an opportunity or abandoning the idea, these measurements are entrepreneurial actions which look for solving the uncertainty about the initial idea. This idea is reproduced on the way from the initial idea to the ultimate idea and new information that is obtained from the media or from the opinions and judgments of others is applied. The creative outcome of this process is to locate some new solutions for the progress of idea to build a framework for this idea using the information available at any point of time. Therefore, the opportunity, as a creative product in entrepreneurship, is perceived as a move (idea + action) on a path which starts from the initial insight and termintates to a complete idea that is about the start and running of a business. Alvarez et al. (2013) distinguish two methods of discovery and creation in entrepreneurial action. The question in creation approach is learn whether market failure means how to create the opportunity through human action.

\section{Table 1}

Creation approach (Alvarez et al., 2013)

\begin{tabular}{|c|c|}
\hline Historical roots & Social constructionism, evolutionary theory, evolutionary realism \\
\hline $\begin{array}{l}\text { Opportunity } \\
\text { resources }\end{array}$ & $\begin{array}{l}\text { The opportunities that are internally enacted are created by entrepreneurs seeking to } \\
\text { exploit them. }\end{array}$ \\
\hline $\begin{array}{l}\text { Primary differences } \\
\text { between } \\
\text { entrepreneurs }\end{array}$ & Differences may be due to opportunity enactment. \\
\hline $\begin{array}{l}\text { Information and } \\
\text { terms of decision } \\
\text { making }\end{array}$ & $\begin{array}{l}\text { Uncertainty: neither possible outcomes nor their probability are clear; knowledge is } \\
\text { not formed yet. Created opportunities form new information specific to the setting } \\
\text { that has not already exist. Decision making is gradual, inductive, and intuitive. }\end{array}$ \\
\hline
\end{tabular}

\section{The path of the evolution of research in creation process}

The pioneers who performed contemporary research on creation process did not concentrate on entrepreneurs from the outset. Rather, they have been focusing on two areas: (1) how people make their own social reality in every setting and (2) the application of evolutionary theory in the emergence of the population of organizations. Then, these two streams merged and formed "evolutionary realism" approach which is the direct intellectual stem in the studies on creation process (Alvarez et al., 2013).

Social constructionism. One of the first statements of social construction can be determined in the book by Berger and Luckmann (1967). The book argues that knowledge, which consists of the everyday experiences to the most advanced results of scientific research, are derived and retained from human interactions. These interactions give meaning to the world around us. Without this meaning, and without the language that happens as the result of our common insight of this meaning, it is not also possible to discuss about the essence of reality. A number of social constructionists argue that the universe is unreal in terms of ontology. In this approach, opportunities are created so that economic 
wealth can be produced socially. This means that when part of the reality is made socially in the society in which the entrepreneur lives, the opportunities become meaningful to entrepreneurs. Weick (1979) describes the way that the behavior of an actor creates the environment in which the actor behaves according to enactment process. People only focus on limited information when they want to understand and describe the behavior of individuals including themselves and its outcomes. Previous interpretations turn into part of the context in which future behavior will be recognized. The context in which we operate is created by our previous behaviors over time through further observation and interpretation. Actions precede interpretations and interpreting those actions is the introduction of new actions. Contemporary research on creation process is based on many perspectives of the constructionism approach. Studies carry out on creation process assume that opportunities are created by entrepreneurs themselves; in this case, there are no opportunities until the entrepreneurs create them through enactment process (Alvarez et al., 2013).

Evolutionary theory: According to Aldrich and Kenworthy (1999), "the emphasis is on the processes of variation, selection, and retention. Variation can be a blind, myopic, or deliberate departure from a daily routine or tradition". Blind variations appear as a result of accident, chance, and conflict. A deliberate variation may happen when individuals or companies build options and look for solutions to problems while restricted rationality recommends that deliberate variation seldom ends in the desired results and hence is myopic in principle (Aldrich \& Kenworthy, 1999). Even some mistakes which lead to oscillations are made if an actor try to copy or reproduce an object accurately. Regardless of their source of origin, these oscillations give some the core of variation. With this variation, selective pressures of some variations could be eliminated while some others survive. The ones that survive can impact on other organizations but only if they are kept (Alvarez et al., 2013) by institutional pressures (Nelson \& Winter, 1982). Evolutionary realism: The pure epistemology of social constructivism maintains a number of features; however, several social scientists agree that this approach to theorizing makes it relatively difficult to make certain testable hypotheses (Godfrey \& Hill, 1995). An alternative, which retains the main features of the enactment process (Weick, 1977), is found for some pure social constructionism. An alternative that makes special and testable predictions of the theory possible at the same time. Evolutionary realism that was developed by Campbell (1974) points out that actors are still generating their reality socially while the authenticity of these social constructions is examined against objective reality or against social constructions of others (Campbell, 1960). In this framework, social scientists can study the interaction between objective constraints and socially made constrains (such as market demand) on individuals and their socially constructed meaning. This issue that built reality of an individual may impact on the social constructions of others can be examined specifically (Azevedo, 2002; Alvarez et al., 2013).

\section{Entrepreneurial actions in creation theory}

Alvarez and Barney (2007) explaine seven entrepreneurial actions that are generally regarded as the most important actions for all entrepreneurs seeking to create opportunity based on creation theory:

\subsection{Leadership}

Many leadership skills may be important regardless of the kind of opportunity while the importance of some of these skills relies on the essence of opportunity. High level of skill in the existing industry or market that matters in exploiting discovery opportunities is not an essential skill for determining the opportunities of creation because the expertise required for opportunity creation is usually recognized after the emergence of opportunity from enactment process. In this setting, leadership is based on experience in managing matters in enactment process; that is the capability of the leader to induce creativity and sacrifice under conditions of uncertainty to the extent that followers believe they can trust a leader. These characteristics feature a charismatic leader rather than an expert leader. 
Charismatic leaders are likely to be more successful than expert executives when participation is required to create opportunities (Alvarez \& Barney, 2007).

\subsection{Decision making}

In this setting, entrepreneurs will decide in at least two ways, making use of biases and heuristics (Busenitz \& Barney, 1997) or engaging in emerging decision making processes (Mintzberg, 1994). Biases and heuristics are used to make decisions in settings where risk-based decision making tools are not applicable. In fact, cognitive psychologists put emphasize on the use of biases and heuristics in settings where the amount of available information is less than the extent that rational decision making approaches can be used. Overconfidence and generalization are two examples of these cognitive biases (Busenitz \& Barney, 1997) that are referred to by creation theory as a way to decide on a company or not to participate in a particular entrepreneurial activity. The second set of tools for decision making in this setting are called bricolage (Baker \& Nelson, 2005) and effectuation (Sarasvathy, 2001). All of these decision making processes are gradual, that is, decision makers make small decisions based on the information they already have. These processes are repeated until the desired result is obtained. And eventually, these methods are inductive, that is, data is collected to assess the quality of the decision after the decision is made. This type of decision making process is the most effective method in the setting of high uncertainty or caution (Alvarez and Barney, 2007).

\subsection{Human resource management}

In creation setting, entrepreneurs do not have the ability to predict the specific types of skills that are required to exploit the opportunity. Therefore, they cannot recruit people based on their specific expertise. In this setting, entrepreneurs seek to recruit individuals with a lot of human capital and those who have high flexibility. Moreover, since it is difficult to explain the nature of the opportunity that is being created for human resources, entrepreneurs seek to recruit individuals from their social networks in this setting (Alvarez \& Barney, 2007).

\subsection{Strategy}

Strategy plays a different role in the setting of creation because historical and current information is not available or is not useful to explain the nature of the opportunity. In this setting, making use of traditional forms of strategic planning may be harmful or even misleading. In creation theory, entrepreneurs are not responsible to combine pre-existing knowledge and information but they are responsible to ask the right questions, design new tests, be flexible and adaptable, and have capacity to intake and learn (Alvarez \& Barney, 2007). This does not mean that entrepreneurs who operate under uncertainty settings do not have plans. Although, instead of accurate documentation, which includes advanced financial planning and market segmentation analysis, creation theory points to the fact that business plans developed under uncertainty settings are a simpler guide to entrepreneurial behavior. In this setting, planning refers to the general direction that entrepreneurs think they are likely to move in but it may have a great deal of basic variations. During the creation process, entrepreneurs may not only have to re-define their potential customers, but they may also have to make variation in the industry, market, or their core technology (Alvarez \& Barney, 2007).

\subsection{Financing}

Creation theory suggests that foreign sources of traditional capital, such as banks or venture capital firms, are less likely to finance entrepreneurs under precarious uncertainty settings (Bhide, 1992). In this setting, it is very difficult or impossible to overcome information asymmetries that limit the ability of external investors to invest in entrepreneurial activities because much of this knowledge and information still needs to be created. Since entrepreneurs themselves are not aware of the nature of the 
opportunities they are planning to exploit, they are not able to explain the nature of these opportunities to the external resources of capital. Therefore, these entrepreneurs rarely acquire the necessary financial resources from external resources of capital. Bootstrapping is the most common way of financing for these entrepreneurs. In bootstrapping, entrepreneurs finance activities from their wealth or the wealth of people with whom they have close links (Bhide, 1992). In creation theory, the specific business that the entrepreneur plans to follow may vary considerably over time. In this setting, it is essential to have flexible investors who are interested in accepting the variations that the entrepreneur may face during the enactment process. In fact, Bhide (1992) argues that those entrepreneurs who work under the settings associated with creation theory may harm their abilities to grow with external financing because in this case, these entrepreneurs will need to exploit a designated opportunity based on the requirements of external suppliers even if this opportunity is not as valuable as it should be (Alvarez \& Barney, 2007).

\subsection{Marketing}

The effectiveness of marketing efforts relies on the settings under which the entrepreneur operates. In creation setting, instead of examining how the external shocks to an industry or market creates opportunities in the marketing mix, namely, product, price, distribution, promotion, and customer service, entrepreneur uses these marketing mix features to explore possible opportunities for creation. For instance, in creation process, an entrepreneur may change his/her distribution model similar to what happened with the introduction of the Internet. Although marketing mix features are not the only source of assumptions about how to generate opportunities, this marketing mix is an essential part for making these assumptions (Alvarez \& Barney, 2007).

\subsection{Sustainable competitive advantage}

Entry barrier creation, confidentiality, and execution speed are less important for entrepreneurs who operate in creation setting. In addition, the path-dependent nature of the opportunity creation process leads to implicit learning which is not known for entrepreneurs who were not involved in creation process (Arthur, 1989; Alvarez \& Barney, 2007).

\section{Table 2}

Effective entrepreneurial actions in creation context (Alvarez \& Barney, 2007)

\begin{tabular}{cc}
\hline Leadership & Based on charisma \\
$\begin{array}{c}\text { Decision making } \\
\begin{array}{c}\text { Human resources } \\
\text { actions }\end{array}\end{array}$ & $\begin{array}{r}\text { Reiterative, inductive, and gradual decision making; making use of biases and } \\
\text { heuristic methods; the importance of acceptable damages }\end{array}$ \\
$\begin{array}{c}\text { Strategy } \\
\text { Financing }\end{array}$ & $\begin{array}{c}\text { Emerging and changing } \\
\text { network. }\end{array}$ \\
$\begin{array}{c}\text { Marketing } \\
\text { Bootstrapping and making use of the resources of "friends, family, and fools". } \\
\text { Sustainable competitive } \\
\text { advantage }\end{array}$ & $\begin{array}{c}\text { Marketing mix may fundamentally change the outcome of new opportunities that } \\
\text { emerge. }\end{array}$ \\
\hline
\end{tabular}

\section{Model of effective entrepreneurial actions in creation context}

The following model is drawn up by considering the studies and effective entrepreneurial actions in the setting of entrepreneurial opportunity creation. This model could be taken as a basis for designing conceptual models of other future research. 


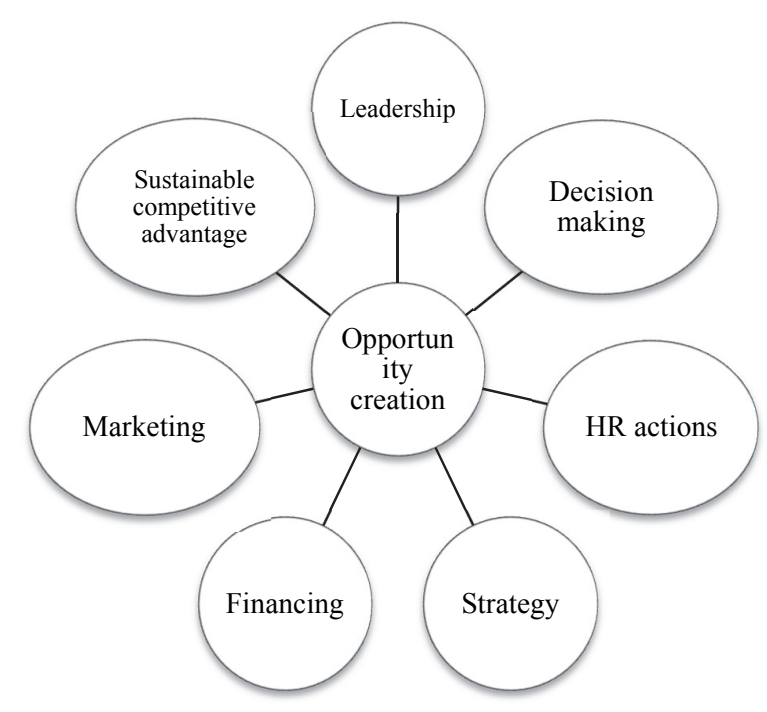

Fig. 2. Model of effective entrepreneurial actions in creation setting

\subsection{Methodology}

The present research is applicable, descriptive, and survey oriented in terms of purpose. It is applicable because it addresses applying the existing theories. It is also descriptive because the researcher has described the existing setting only as a descriptor and without manipulating the research variables. This research is also a survey because the researcher has used a systematic data collection method, which is a questionnaire.

Desk research method and questionnaire have been used to collect information and required data. In the first step, the previous studies have been used to identify effective entrepreneurial actions in creation setting so that the researcher can take the most advantage of the results of other researchers. After identifying the seven actions, DEMATLE Method was used to construct actions so that the domino effect could be structured and characterized.

The specialized comments of 15 experts and specialists on entrepreneurship, opportunity creation, and entrepreneurial actions who were the authors of articles and papers on mentioned fields were used in order to construct entrepreneurial actions. Non-random judgmental sampling method was used to select these individuals. That is, these people were selected based on their knowledge and expertise.

When effective entrepreneurial actions in creation setting are identified, they should be constructed to determine what factors have higher impacts so that entrepreneurs and policy makers of entrepreneurship development and opportunity creation can concentrate on these factors. Therefore, a pair-wise comparison matrix questionnaire for DEMATLE Method was distributed among the experts and then sequencing, the effectiveness structure, and the effectiveness intensity of these actions were calculated using this technique.

The steps of DEMATLE Method are briefly described in the following:

\section{Step 1: Constructing a survey matrix of respondents}

In the first step, each respondent is asked to indicate the direct influence that she/he considers element $i$ has on element $j$. This influence can be specified with score $\mathrm{P}_{\mathrm{ij}}$. For example, the influence of element $i$ on element $j$ can be specified using the integers which are between 0 and 4 . Accordingly, number zero indicates that element $i$ does not have any influence on element $j$, number 1 indicates low influence; number 2 indicates average influence; number 3 indicates high influence, and number 4 indicates very 
high influence of element i on element j. Therefore, matrix $\boldsymbol{P}^{\boldsymbol{k}}=\left[\boldsymbol{P}_{\boldsymbol{i j}}\right]_{\boldsymbol{n} \times \boldsymbol{n}}$ will be constructed for each decision maker (Azar et al., 2016).

Step 2: Constructing elementary decision matrix

In fact, this matrix is extracted from the simple average of comments that respondents made in the previous step. We call the elementary decision matrix A, and denote it as $\boldsymbol{A}=\left[\boldsymbol{a}_{\boldsymbol{i} \boldsymbol{j}}\right]_{\boldsymbol{n} \times \boldsymbol{n}}$. Where $\boldsymbol{a}_{\boldsymbol{i} \boldsymbol{j}}=$ $\frac{\mathbf{1}}{\boldsymbol{k}} \sum_{\boldsymbol{k}=\mathbf{1}}^{K} \boldsymbol{P}_{\boldsymbol{i j}}$ (Azar et al., 2016).

Step 3: Calculating elementary influence matrix

Elementary influence matrix D $\left(\boldsymbol{D}=\left[\boldsymbol{d}_{\boldsymbol{i j}}\right]_{\boldsymbol{n} \times \boldsymbol{n}}\right)$ will be obtained through normalizing elementary decision matrix A. In this matrix, all elements that lie on the original diameter equal zero. Matrix D denoted the elementary influence of an element including effectiveness and efficacy. Here, the implicit relation between elements of a system can be pictured by drawing a map. The numbers of this matrix indicate the power of the influence of elements.

The matrix D is obtained using the following equations (Azar et al., 2016):

Or

$$
D=S . A \quad, \quad S>0
$$

$$
\begin{aligned}
{\left[d_{i j}\right]_{n \times n} } & =S\left[a_{i j}\right]_{n \times n} \quad, \quad S>0, i, j \in\{1,2, \ldots, n\} \\
S & =\operatorname{Min}\left[\frac{1}{\max _{1 \leq i \leq n}^{\max } \sum_{j=1}^{n}\left|a_{i j}\right|}, \frac{1}{\max _{1 \leq j \leq n} \sum_{i=1}^{n}\left|a_{i j}\right|}\right]
\end{aligned}
$$

Step 4: Extracting the full direct/indirect influence matrix

If the exponent of the elementary influence matrix (D) raises (e.g. $\left.D^{2}, D^{3}, \ldots, D^{\infty}\right)$, direct influences of the problem decrease and this ensures convergent solutions to the reverse matrix. Therefore, an infinite set of direct and indirect influences can be created. Total influence matrix that is called $\mathrm{T}$ is obtained from the following equation:

where $I$ is identity matrix.

$$
T=D+D^{2}+D^{3}+\ldots+D^{m}=D(I-D)^{-1}, m \rightarrow \infty
$$

If the sums of the rows and columns in the matrix T are denoted by vectors $r$ and $d$, respectively, then we have:

$$
\begin{gathered}
T=\left[t_{i j}\right]_{n \times n} \\
R=\left[r_{i}\right]_{n \times 1}=\left(\sum_{j=1}^{n} t_{i j}\right)_{n \times 1} \\
D=\left[d_{j}\right]_{1 \times n}=\left(\sum_{i=1}^{n} t_{i j}\right)_{1 \times n}^{n}
\end{gathered}
$$

If $r_{i}$ denotes the row sum of $i^{\text {th }}$ row in matrix $T$, then $r_{i}$ represents the sum of direct and indirect influences of factor $i$ on other factors (criteria). If $d_{j}$ denotes the column sum of the $j^{\text {th }}$ column in matrix $T$, then $\mathrm{d}_{\mathrm{j}}$ represents the sum of direct and indirect influences of other factors on factor $j$. When $\mathrm{i}=\mathrm{j}$, then the sum of the rows and columns $\left(\mathrm{r}_{\mathrm{i}}+\mathrm{di}\right)$ represents the index of the power of effectiveness and efficacy. In other words, $r_{i}+d_{i}$ shows the degree of the central role played by element $i$ in this problem. Therefore, if $\left(\mathrm{r}_{\mathrm{i}}-\mathrm{d}_{\mathrm{i}}\right)$ is positive, it indicates that element $\mathrm{i}$ influences other elements, and if it is negative, it shows that other elements influence element $i$ (Azar et al., 2016).

Step 5: Determining threshold value and plotting influence-relationship map By determining threshold value, it is necessary to explain the structure of the relation between the elements. Based on the matrix $T$, each $\mathrm{t}_{\mathrm{ij}}$ element in matrix $T$ explains the way element $i$ influences 
element j. To reduce the complexity of Influence-Relationship Map (IRM), decision makers should set a threshold value for the levels of effectiveness. Accordingly, only those elements whose influence level on matrix $\mathrm{T}$ is greater than threshold value can be selected and displayed in IRM.In this matrix, $r_{\mathrm{i}}+d_{\mathrm{i}}$ lies on axis $x$, and $\mathrm{r}_{\mathrm{i}}-\mathrm{d}_{\mathrm{i}}$ lies on axis $y$. Values of $r+d$ represent the significance of each factor and the more the value of factor, the more significant it is (Aghaei \& Naeini, 2018).

Step 6: Analysis

In order to determine the relation between factors, the assumptions of this technique should be taken into consideration as follows:

1. If $\boldsymbol{r}_{\boldsymbol{i}}-\boldsymbol{d}_{\boldsymbol{i}}<\mathbf{0}$ and $\boldsymbol{r}_{\boldsymbol{i}}+\boldsymbol{d}_{\boldsymbol{i}}=\boldsymbol{M}$ (M is a remarkably large number), then element $\mathrm{i}$ is the main problem and should be solved.

2. If $\boldsymbol{r}_{\boldsymbol{i}}-\boldsymbol{d}_{\boldsymbol{i}}>\mathbf{0}$ and $\boldsymbol{r}_{\boldsymbol{i}}+\boldsymbol{d}_{\boldsymbol{i}}=\boldsymbol{M}$ (M is a remarkably large number), then element i solves the main problem and should be in priority.

3. If $\boldsymbol{r}_{\boldsymbol{i}}-\boldsymbol{d}_{\boldsymbol{i}}<\mathbf{0}$ and $\boldsymbol{r}_{\boldsymbol{i}}+\boldsymbol{d}_{\boldsymbol{i}}=\boldsymbol{\varepsilon}$ ( $\boldsymbol{\varepsilon}$ is a small number), then element $\mathrm{i}$ is an independent element influenced by other elements.

4. If $\boldsymbol{r}_{\boldsymbol{i}}-\boldsymbol{d}_{\boldsymbol{i}}>\mathbf{0}$ and $\boldsymbol{r}_{\boldsymbol{i}}+\boldsymbol{d}_{\boldsymbol{i}}=\boldsymbol{\varepsilon}$ ( $\boldsymbol{\varepsilon}$ is a small number), then element $\mathrm{i}$ is an independent element influencing a few number of other elements (Ghassemi \& Darvishpour, 2018).

\section{Findings}

The nature and intensity of the effectiveness of entrepreneurial actions have been identified in this section. Novel DEMATEL Method has been used to determine the effectiveness and its intensity. After the relationships between the actions were identified based on expert opinion through a pair-wise comparison, the average results were used as the input of DEMATEL Solver software and the results are presented step-by-step in the following tables.

Table 3

Step 1: Constructing a direct relation matrix

\begin{tabular}{|c|c|c|c|c|c|c|c|c|}
\hline Matrix & Leadership & $\begin{array}{c}\text { Decision } \\
\text { making }\end{array}$ & $\begin{array}{c}\mathrm{HR} \\
\text { actions }\end{array}$ & Strategy & Financing & Marketing & $\begin{array}{c}\text { Competitive } \\
\text { advantage }\end{array}$ & Total \\
\hline Leadership & 0 & 2.35 & 2.276 & 2.103 & 2.251 & 2.327 & 1.362 & 12.669 \\
\hline $\begin{array}{l}\text { Decision } \\
\text { making }\end{array}$ & 0.465 & 0 & 2.426 & 1.024 & 2.318 & 2.114 & 1.185 & 9.532 \\
\hline HR actions & 2.219 & 1.045 & 0 & 0.427 & 0.453 & 0.643 & 1.219 & 6.006 \\
\hline Strategy & 1.278 & 1.021 & 2.164 & 0 & 1.937 & 1.946 & 0.946 & 9.292 \\
\hline Financing & 0.236 & 1.214 & 1.436 & 0.467 & 0 & 1.038 & 0.784 & 5.175 \\
\hline Marketing & 1.027 & 0.426 & 1.378 & 0.846 & 0.857 & 0 & 0.856 & 5.39 \\
\hline $\begin{array}{l}\text { Competitive } \\
\text { advantage }\end{array}$ & 0.937 & 0.217 & 0.956 & 1.026 & 1.758 & 1.452 & 0 & 6.346 \\
\hline
\end{tabular}

where alpha equals to 0.0789 .

Table 4

Step 2: Normalization or relative intensity of direct relations

\begin{tabular}{cccccccc}
\hline Normal Matrix & Leadership & $\begin{array}{c}\text { Decision } \\
\text { making }\end{array}$ & $\begin{array}{c}\text { HR } \\
\text { actions }\end{array}$ & Strategy & Financing & Marketing & $\begin{array}{c}\text { Competitive } \\
\text { advantage }\end{array}$ \\
\hline Leadership & 0 & 0.1855 & 0.1797 & 0.166 & 0.1777 & 0.1837 & 0.1075 \\
Decision making & 0.0367 & 0 & 0.1915 & 0.0808 & 0.183 & 0.1669 & 0.0935 \\
HR actions & 0.1752 & 0.0825 & 0 & 0.0337 & 0.0358 & 0.0508 & 0.0962 \\
Strategy & 0.1009 & 0.0806 & 0.1708 & 0 & 0.1529 & 0.1536 & 0.0747 \\
Financing & 0.0186 & 0.0958 & 0.1133 & 0.0369 & 0 & 0.0819 & 0.0619 \\
Marketing & 0.0811 & 0.0336 & 0.1088 & 0.0668 & 0.0676 & 0 & 0.0676 \\
Competitive & 0.074 & 0.0171 & 0.0755 & 0.081 & 0.1388 & 0.1146 & 0 \\
advantage & & & & & & & 0 \\
\hline
\end{tabular}


In this step, alpha is multiplied in direct relation matrix.

Table 5

Step 3: Possible Intensity Matrix (Reverse)

\begin{tabular}{cccccccc}
\hline Reverse Matrix & Leadership & $\begin{array}{c}\text { Decision } \\
\text { making }\end{array}$ & $\begin{array}{c}\text { HR } \\
\text { actions }\end{array}$ & Strategy & Financing & Marketing & $\begin{array}{c}\text { Competitive } \\
\text { advantage }\end{array}$ \\
\hline Leadership & 1.1801 & 0.3359 & 0.4379 & 0.3019 & 0.3986 & 0.4056 & 0.275 \\
Decision making & 0.1709 & 1.1221 & 0.3643 & 0.1818 & 0.3275 & 0.3164 & 0.2136 \\
HR actions & 0.2557 & 0.1804 & 1.1584 & 0.1309 & 0.1792 & 0.1924 & 0.1897 \\
Strategy & 0.2285 & 0.2054 & 0.3555 & 1.1153 & 0.3106 & 0.3142 & 0.2017 \\
Financing & 0.099 & 0.1581 & 0.2191 & 0.0998 & 1.1001 & 0.1765 & 0.134 \\
Marketing & 0.162 & 0.1164 & 0.2266 & 0.1365 & 0.1746 & 1.1127 & 0.1463 \\
Competitive & 0.1603 & 0.1096 & 0.2112 & 0.1551 & 0.2464 & 0.2274 & 1.09 \\
advantage & & & & & & & \\
\hline
\end{tabular}

In this step, possible intensity matrix is obtained from direct and indirect relations as reverse $I-M$.

Table 6

Step 4: Matrix of total relations or intensity of direct/indirect relations

\begin{tabular}{ccccccccc}
\hline $\begin{array}{c}\text { Total relations } \\
\text { Matrix }\end{array}$ & Leadership & $\begin{array}{c}\text { Decision } \\
\text { making }\end{array}$ & $\begin{array}{c}\text { HR } \\
\text { actions }\end{array}$ & Strategy & Financing & Marketing & $\begin{array}{c}\text { Competitive } \\
\text { advantage }\end{array}$ & R \\
\hline Leadership & 0.1801 & 0.3359 & 0.4379 & 0.3019 & 0.3986 & 0.4056 & 0.275 & 2.335 \\
Decision making & 0.1709 & 0.1221 & 0.3643 & 0.1818 & 0.3275 & 0.3164 & 0.2136 & 1.6965 \\
HR actions & 0.2557 & 0.1804 & 0.1584 & 0.1309 & 0.1792 & 0.1924 & 0.1897 & 1.2866 \\
Strategy & 0.2285 & 0.2054 & 0.3555 & 0.1153 & 0.3106 & 0.3142 & 0.2017 & 1.7311 \\
Financing & 0.099 & 0.1581 & 0.2191 & 0.0998 & 0.1001 & 0.1765 & 0.134 & 0.9865 \\
Marketing & 0.162 & 0.1164 & 0.2266 & 0.1365 & 0.1746 & 0.1127 & 0.1463 & 1.0751 \\
Competitive & 0.1603 & 0.1096 & 0.2112 & 0.1551 & 0.2464 & 0.2274 & 0.09 & 1.2001 \\
advantage & 1.2564 & 1.2279 & 1.973 & 1.1213 & 1.7371 & 1.7451 & 1.2503 & \\
\hline J & & & & & & & &
\end{tabular}

In this step, relative intensity matrix is obtained from direct and indirect relations (total relations) as reverse $M(I-M)$.

Table 7

Step 5: Matrix of the intensity of indirect relations

\begin{tabular}{cccccccc}
\hline $\begin{array}{c}\text { Intensity of indirect } \\
\text { relations }\end{array}$ & Leadership & $\begin{array}{c}\text { Decision } \\
\text { making }\end{array}$ & $\begin{array}{c}\text { HR } \\
\text { actions }\end{array}$ & Strategy & Financing & Marketing & $\begin{array}{c}\text { Competitive } \\
\text { advantage }\end{array}$ \\
\hline Leadership & 0.1801 & 0.1504 & 0.2583 & 0.1359 & 0.2209 & 0.2219 & 0.1675 \\
Decision making & 0.1342 & 0.1221 & 0.1728 & 0.101 & 0.1446 & 0.1495 & 0.1201 \\
HR actions & 0.0805 & 0.0979 & 0.1584 & 0.0972 & 0.1434 & 0.1416 & 0.0935 \\
Strategy & 0.1276 & 0.1248 & 0.1847 & 0.1153 & 0.1577 & 0.1605 & 0.127 \\
Financing & 0.0803 & 0.0623 & 0.1058 & 0.0629 & 0.1001 & 0.0946 & 0.0721 \\
Marketing & 0.0809 & 0.0828 & 0.1178 & 0.0697 & 0.107 & 0.1127 & 0.0787 \\
Competitive advantage & 0.0863 & 0.0925 & 0.1357 & 0.0741 & 0.1077 & 0.1128 & 0.09 \\
\hline
\end{tabular}

In this step, relative intensity matrix is calculated from indirect relations which is obtained as reverse $\mathrm{M}^{\wedge} 2(\mathrm{I}-\mathrm{M})$.

Table 8

Step 6. The result

\begin{tabular}{ccccc}
\hline Final result & $\mathrm{R}$ & $\mathrm{J}$ & $\mathrm{R}+\mathrm{J}$ & $\mathrm{R}-\mathrm{J}$ \\
\hline Leadership & 2.335 & 1.2564 & 3.5914 & 1.0786 \\
Decision making & 1.7311 & 1.1213 & 2.8523 & 0.6098 \\
HR actions & 1.6965 & 1.2279 & 2.9244 & 0.4687 \\
Strategy & 1.2866 & 1.973 & 3.2596 & -0.6863 \\
Financing & 1.2001 & 1.2503 & 2.4503 & -0.0502 \\
Marketing & 1.0751 & 1.7451 & 2.8202 & -0.6699 \\
Competitive advantage & 0.9865 & 1.7371 & 2.7237 & -0.7506 \\
\hline
\end{tabular}

The chart of the relations of model components is also plotted as following: 


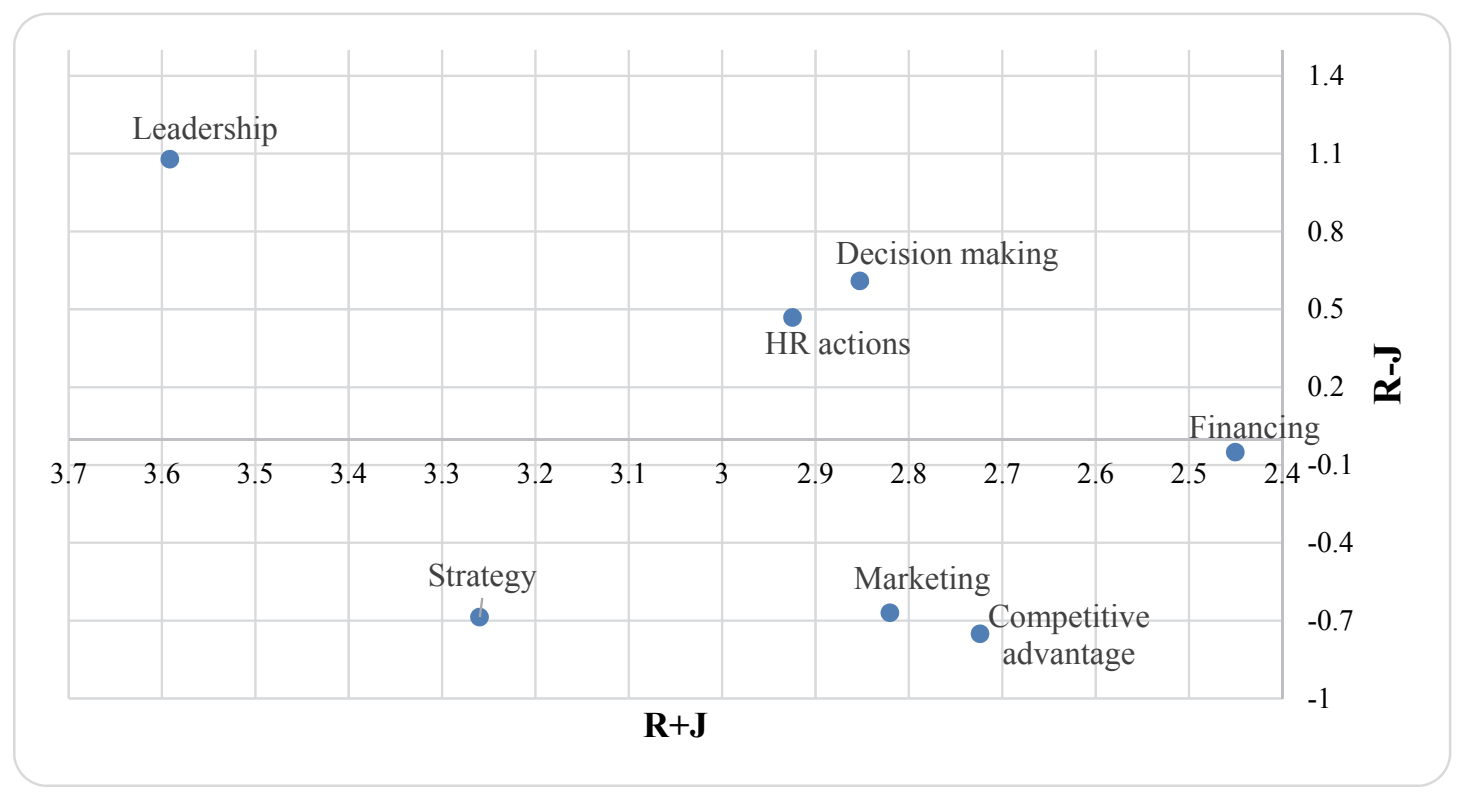

Fig. 3. Effectiveness chart of effective factors

The results showed that the right factors influence a larger number of factors and the factors located on top of intensity table have a greater influence on other factors. This means that leadership action influences all 6 actions and it also has the most intense influence on other factors. Sustainable competitive advantage will not influence any action and the influence of financing action is the least among the actions studied in this paper.

\section{Discussion and conclusion}

Technological entrepreneurship defines as identifying technology-driven entrepreneurial opportunities through recognition, discovery, or creation and exploiting those opportunities. Moreover, technological entrepreneur refers to managing small businesses owned by engineers and scientists, introducing some applications for a specific technology, starting new technology-driven businesses, introducing new applications, exploiting the opportunities that all rely on scientific and technical knowledge, and working with others to create technology or making variation in technology. Creation of entrepreneurial opportunities is one of the most effective settings in technological entrepreneurship. The purpose of opportunity creation theory is to outline the actions that entrepreneurs take to form and exploit opportunities. Created opportunities refer to opportunities in which none of the parties of supply and demand do not exist clearly and obviously; then one or both of them must be created and several economic inventions should take place in the way of marketing, franchising, etc. so that opportunity can be created. This perception of opportunity deals with the creation of new markets (Sarasvathy et al., 2003). Therefore, theories of entrepreneurial opportunity creation were studied in this research. Moreover, the evolutionary path of opportunity creation theories was also examined. Finally, previous studies and theories of other researches on entrepreneurial actions were addressed in order to identify entrepreneurial actions influencing opportunity creation and seven main effective entrepreneurial actions in opportunity creation setting were identified. Examinations have revealed that leadership action has the greatest influence on other entrepreneurial actions in opportunity creation. Furthermore, decision making and strategy were ranked second and third. Based on the results, in order to strengthen entrepreneurial opportunity creation, we must concentrate and plan on effective actions such as leadership, decision making, and strategy.

\section{References}

Aghaei, S., \& Naeini, A. (2018). Consumer attitudes toward new pasta products in Iran market: A qualitative and quantitative study. Management Science Letters, 8(2), 109-120. 
Aldrich, H. E., \& Kenworthy, A. (1999). The accidental entrepreneur: Campbellian antinomies and organizational foundings. Variations in organization science: In honor of Donald T. Campbell, 19-33.

Alvarez, S. A., \& Barney, J. B. (2007). Discovery and creation: Alternative theories of entrepreneurial action. Strategic entrepreneurship journal, 1(1-2), 11-26.

Alvarez, S. A., Barney, J. B., \& Anderson, P. (2013). Forming and exploiting opportunities: The implications of discovery and creation processes for entrepreneurial and organizational research. Organization Science, 24(1), 301-317.

Alvarez, S. A., Young, S. L., \& Woolley, J. L. (2015). Opportunities and institutions: A co-creation story of the king crab industry. Journal of Business Venturing, 30(1), 95-112.

Arthur, W. B. (1989). Competing technologies, increasing returns, and lock-in by historical events. The economic journal, 99(394), 116-131.

Azar, A., Khosravani, F. \& Jalali, R. (2016). Soft Operational Research: Problem Structuring Methods, $2^{\text {nd }}$ edit, Industrial Management Institution Pub Co., Tehran.

Azevedo, J. (2002). Updating organizational epistemology. Companion to organizations, 715-732.

Baker, T., \& Nelson, R. E. (2005). Creating something from nothing: Resource construction through entrepreneurial bricolage. Administrative science quarterly, 50(3), 329-366.

Berger, P. L., \& Luckmann, T. (1967). The social construction ofreality. New York.

Bhide, A. (1992). Bootstrap finance: the art of start-ups. Harvard business review, 70(6), 109-117.

Blanco, S. (2007). How techno-entrepreneurs build a potentially exciting future. Handbook of Research on Techno-Entrepreneurship, 1, 3-25.

Burgelman, R. A., Christensen, C. M., \& Wheelwright, S. C. (2004). Integrating technology and strategy: a general management perspective. Strategic Management of Technology and Innovation, 208.

Busenitz, L. W., \& Barney, J. B. (1997). Differences between entrepreneurs and managers in large organizations: Biases and heuristics in strategic decision-making. Journal of business venturing, 12(1), 9-30.

Campbell, D. T. (1960). Blind variation and selective retentions in creative thought as in other knowledge processes. Psychological review, 67(6), 380.

Campbell, D. T. (1974). Evolutionary epistemology. P. A. Schilpp, ed. The Philosophy of Karl Popper, Vol. 14. Open Court, La Salle, IL, 413-463

Davidsson, P. (2004). Researching entrepreneurship. New York: Springer.

Dimov, D. (2007). Beyond the single-person, single-insight attribution in understanding entrepreneurial opportunities. Entrepreneurship Theory and Practice, 31(5), 713-731.

Ghassemi, A., \& Darvishpour, A. (2018). A novel approach for risk evaluation and risk response planning in a geothermal drilling project using DEMATEL and fuzzy ANP. Decision Science Letters, 7(3), 225-242.

Godfrey, P. C., \& Hill, C. W. (1995). The problem of unobservables in strategic management research. Strategic management journal, 16(7), 519-533.

Hitt, M. A., Ireland, R. D., Camp, S. M., \& Sexton, D. L. (2001). Strategic entrepreneurship: Entrepreneurial strategies for wealth creation. Strategic management journal, 22(6-7), 479-491.

Mintzberg, H., \& Waters, J. A. (1985). Of strategies, deliberate and emergent. Strategic management journal, 6(3), 257-272.

Nelson Richard, R., \& Winter Sidney, G. (1982). An evolutionary theory of economic change. Harvard Business School Press, Cambridge.

Petti, C. (Ed.). (2009). Cases in technological entrepreneurship: Converting ideas into value. Edward Elgar Publishing.

Sarasvathy, S. D. (2001). Causation and effectuation: Toward a theoretical shift from economic inevitability to entrepreneurial contingency. Academy of management Review, 26(2), 243-263.

Sarasvathy, S. D., Dew, N., Velamuri, S. R., \& Venkataraman, S. (2003). Three views of entrepreneurial opportunity. In Handbook of entrepreneurship research (pp. 141-160). Springer US.

Weick, K. (1979). The social psychology of organisations. Reading, Mass: Addison-Westly.

Weick, K. E. (1977). Enactment processes in organizations. New directions in organizational behavior, 267, 300.

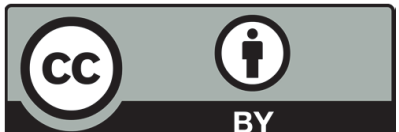

(C) 2018 by the authors; licensee Growing Science, Canada. This is an open access article distributed under the terms and conditions of the Creative Commons Attribution (CC-BY) license (http://creativecommons.org/licenses/by/4.0/). 